\title{
Modified technique for laparoscopic running vesicourethral anastomosis
}

\author{
Tomasz Golabek ${ }^{1}$, Piotr Jarecki ${ }^{2}$, Jaroslaw Jaskulski ${ }^{3}$, Przemyslaw Dudek ${ }^{1}$, Tomasz Szopiński ${ }^{1}$, Piotr Chłosta ${ }^{1}$ \\ ${ }^{1}$ Department of Urology, Jagiellonian University Medical College, Krakow, Poland \\ ${ }^{2}$ Department of Urology, City Hospital, Koscierzyna, Poland \\ ${ }^{3}$ Department of Urology, Institute of Oncology, Kielce, Poland
}

Videosurgery Miniinv 2014; 9 (3): 357-361

DOI: 10.5114/wiitm.2014.43129

\begin{abstract}
Introduction: A vesicourethral anastomosis is the most challenging and time-consuming step of radical prostatectomy. In 2003, van Velthoven introduced his own technique of connecting the bladder neck with the membranous urethra, which has remained the most popular method since. Despite being effective, this method is time consuming and is not free from the risk of complications.

Aim: Here we describe our technique for laparoscopic vesicourethral anastomosis using a running suture as an alternative to the traditional approach.

Material and methods: The vesicourethral anastomosis is created using a running stitch placed first at the 5 o'clock position on the posterolateral aspect of the bladder outside-in and then through the urethra at the same location inside-out. Proceeding anticlockwise, the running suture is placed 5 times more through both the bladder neck and the urethra in a similar fashion until it meets the free end at the 5 o'clock position. A single knot is then tied outside the bladder.

Results: The anastomotic technique has been used in 28 patients with clinically organ confined prostate cancer. The mean anastomosis time was $9.53 \mathrm{~min}$, the mean operative time was $155.20 \mathrm{~min}$, the mean drain permanence was 2.71 days, and the mean catheterisation time was 17.28 days. Continence rate 3 months after surgery was $92.85 \%$, and $100 \%$ at 6- and 12-month follow-up visits.

Conclusions: We describe a safe, feasible and efficient technique for vesicourethral anastomosis. Further studies on a larger group of patients are needed to confirm our encouraging preliminary results.
\end{abstract}

Key words: vesicourethral anastomosis, laparoscopic radical prostatectomy, surgical technique.

\section{Introduction}

Prostate cancer $(\mathrm{PCa})$ is one of the most commonly diagnosed malignancies in men [1]. In the USA and several Western European countries the incidence of PCa exceeds incidence rates of the remainder of malignant neoplasms among the male population [2, 3]. The PCa remains the second most prevalent cause of death in men [4]. Moreover, an increase in PCa-related mortality has been observed since 1985 worldwide and also in the countries where PCa diagnosis rates are relatively low [5]. Currently, $81 \%$ of $P C$ a cases are diagnosed at an early stage allowing for effective treatment $[6,7]$.

Laparoscopic radical prostatectomy, a novel and minimally invasive surgical technique, is the first line treatment option offered to men with PCa confined to the prostate [8-12]. Endoscopic surgery offers

\section{Address for correspondence}

Tomasz Golabek MD, PhD, Department of Urology, Jagiellonian University Medical College, 18 Grzegorzecka St, 31-531 Krakow, Poland,

phone: +48 690999 122, e-mail: elementare@op.pl 
magnification of the operative field and enables more precise identification and dissection of the anatomical structures [13-16]. Not only does it provide excellent oncological outcomes but it also shortens patients' hospital stay and increases chances of prompt full recovery [12].

Still, despite its minimal invasiveness, laparoscopic radical prostatectomy carries the risk of intra- and postoperative complications and requires a high level of skills in laparoscopic techniques. The complications of the surgery worst affecting the patient's quality of life are a stricture of the bladder neck or urinary incontinence, the occurrence of which mainly depends on the success of urine outflow reconstruction [15, 17-19]. Currently there are few methods for vesicourethral anastomosis reconstruction during laparoscopic radical prostatectomy [8-10]. In 2003, van Velthoven introduced his own technique of connecting the bladder neck with the membranous urethra, which has remained the most popular method since [9].

The anastomosis is created using a running stitch consisting of two tied sutures from 12 insertion points, commencing on the posterior bladder wall and finishing on the anterior bladder wall. Despite being effective, this method is time consuming and is not free from the risk of complications $[9,18,20]$.

\section{Aim}

We describe our technique for laparoscopic running vesicourethral anastomosis as an alternative to the traditional approach.

Table I. Patient demographics

\begin{tabular}{|lc|}
\hline Variable & Value \\
\hline Age, mean (SD) [years] & $59.39(5.74)$ \\
\hline PSA, mean (SD) [ng/ml] & $9.70(8.34)$ \\
\hline Median Gleason score & 6 \\
\hline Preoperative Gleason score [\%]: & 7.14 \\
\hline 4 & 17.85 \\
\hline 5 & 50.0 \\
\hline 6 & 17.85 \\
\hline 7 & 3.57 \\
\hline 8 & 3.57 \\
\hline 9
\end{tabular}

SD - standard deviation

\section{Material and methods}

A total of 28 patients underwent extraperitoneal laparoscopic radical prostatectomy with running urethrovesical anastomosis in our own modification for clinically localised prostate cancer (Table I). All procedures were performed by a single senior surgeon. Perioperative parameters such as operative time, blood loss, transfusion and conversion rates, drainage output, and catheterisation time, were reviewed from our prospectively maintained database. When drainage output was less than $50 \mathrm{ml}$, the drain was removed. The bladder catheter was removed without performing cystography.

Urinary continence status was assessed 3, 6 and 12 months after laparoscopic radical prostatectomy. Postoperative continence was defined as no need for the pads.

\section{Surgical technique}

After the prostate is extirpated and haemostasis is secured, the bladder neck and the urethra are exposed for the anastomosis. The running stitch (2-0 polyglactin, an absorbable synthetic suture) is placed first at the 5 o'clock position on the posterolateral aspect of the bladder outside-in and then through the urethra at the same location inside-out (Figure 1). Proceeding anticlockwise, the running suture, always driven full thickness, is placed 5 times more through both the bladder neck and the urethra in a similar fashion until it meets the free end at the 5 o'clock position. Just before placing the last stitch, a $18 \mathrm{Fr}$ Foley catheter is inserted into the bladder and its
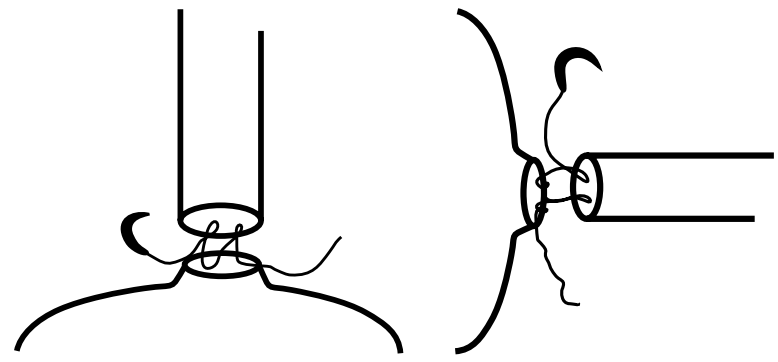

Figure 1. Coronal and transverse views illustrating the technique for performing the running single knot vesicourethral anastomosis. The stitch is placed first at the 5 o'clock position on the posterolateral aspect of the bladder outside-in and then through the urethra at the same location inside-out. Proceeding anticlockwise, the running suture is always driven full thickness 


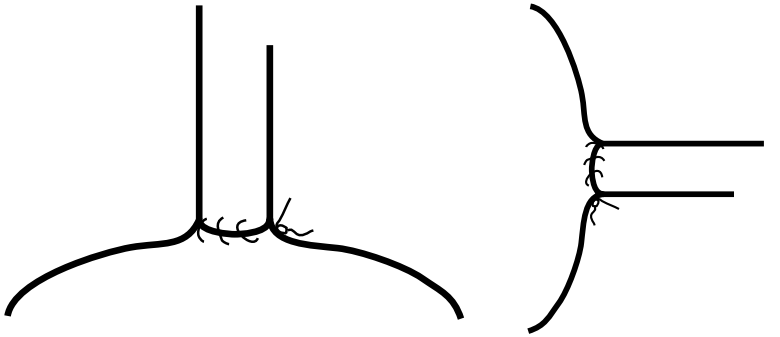

Figure 2. Coronal and transverse views illustrating the technique for performing the running single knot vesicourethral anastomosis. The running suture is placed 6 times through both the bladder neck and the urethra until its two ends meet at the 5 o'clock position. Both ends of the suture are then tied outside the bladder

balloon inflated with $10 \mathrm{ml}$ of distilled water. Both ends of the suture are then tied outside the bladder (Figure 2). To prevent loose anastomosis, gentle traction is applied to the free end of the stitch at the 5 o'clock position as it enters the bladder throughout the procedure. Upon completion of the anastomosis, the integrity of the urinary reconstruction is tested by filling the bladder with $200 \mathrm{ml}$ of normal saline. A $20 \mathrm{Fr}$ Redon drain is placed in the pelvis by the anastomosis.

Perioperative parameters such as operative time, transfusion and conversion rates, catheterisation time, pathological results and positive surgical margin rate (+SMR) were reviewed from our prospectively maintained database. Urinary continence status was assessed 3, 6 and 12 months after laparoscopic radical prostatectomy. Postoperative continence was defined as the absence of the need for any pads.

\section{Results}

Patients' demographic data are presented in Table II and intraoperative data in Table III. The mean patient age was 59 years (range: 47-70). The most common preoperative Gleason sum was 6 . The mean anastomosis time was 9.53 min (range: 5-17). The mean operative time (from skin incision to skin closure) was 155 min (range: 90-210). The extraperitoneal laparoscopic radical prostatectomy with running urethrovesical anastomosis was successfully performed in all patients, and none of the cases required conversion to open surgery. The mean blood loss was $167.03 \mathrm{ml}$ (range: 110-320). The total perioperative transfusion rate was $3.57 \%$
Table II. Intraoperative data

\begin{tabular}{|lc|}
\hline Variable & Value \\
\hline Anastomosis time, mean (SD) [min] & $9.53(3.80)$ \\
\hline Operative time, mean (SD) [min] & $155.20(35.39)$ \\
\hline Blood loss, mean (SD) [ml] & $167.03(61.19)$ \\
\hline Transfusion rate [\%] & $0 / 28$ \\
\hline Conversion rate [\%] & $0 / 28$ \\
\hline Drainage time, mean (SD) [days] & $2.71(0.6)$ \\
\hline LOS, mean (SD) [days] & $7.74(2.04)$ \\
\hline Catheterisation time, mean (SD) [days] & $17.28(3.87)$ \\
\hline
\end{tabular}

SD - standard deviation, LOS - length of hospital stay

Table III. Oncologic results

\begin{tabular}{|lc|}
\hline Variable & Value \\
\hline pT2a, $n(\%)$ & $4(14.28)$ \\
\hline pT2b, $n(\%)$ & $2(7.14)$ \\
\hline pT2c, $n(\%)$ & $21(75)$ \\
\hline pT3a, $n(\%)$ & $1(3.57)$ \\
\hline pT3b, $n(\%)$ & $0(0)$ \\
\hline pT4a, $n(\%)$ & $0(0)$ \\
\hline Median Gleason score & 6 \\
\hline Postoperative Gleason score [\%]: & 10.71 \\
\hline 4 & 17.85 \\
\hline 5 & 50.0 \\
\hline 6 & 17.85 \\
\hline 7 & 0 \\
\hline 8 & 3.57 \\
\hline 9
\end{tabular}

(1 patient), and no patient required blood transfusion intraoperatively. There were no intraoperative complications. The mean drainage time was 2.71 days (range: $2-4)$. The mean hospital stay was 7 days (range: 5-14), and the mean catheter time was 17 days (range: 10-21).

Oncological results are presented in Table III. The most common Gleason sum determined postoperatively was 6 . The distribution of pathological stages was $96.43 \%$ pT2, 3.57\% pT3. Only 2 patients were incontinent 3 months after surgery, and all men had complete urinary control at 6 and 12 months assessments. There was no urethral stricture recorded during the entire follow-up. 


\section{Discussion}

The anastomosis of the urethral stump to the bladder neck is a challenging, yet a critical step during the radical prostatectomy. Regardless of the method of surgery being performed, re-establishment of continuity of the lower urinary tract should be easy to learn and to do, as well as safe and effective in preventing future urinary leakage.

Our running suture single knot technique further simplifies the reconstruction-making process as only one stitch is used and it takes just six passes through both elements of the anastomosis, with only one knot tied at the end of the procedure. The average time of anastomosis was $9.53 \mathrm{~min}$ and it is 2 to 3 times shorter than with other reconstruction techniques being reported [9, 21-23]. With this method, we found that gentle traction applied to the free end of the stitch at the 5 o'clock position throughout the procedure, in order to prevent anastomosis from loosening and consequently ensuring watertightness of the vesicourethral fixation, is of paramount importance.

Upon completion of the surgery we place a pelvic drain in the anastomotic site, which is removed when drainage is less than $50 \mathrm{ml} /$ day. Low creatinine level in the drain fluid checked routinely just before tube removal confirms effective vesicourethral reconstruction. Our patients remain catheterised for 10 days following discharge from the hospital, even though we are aware of the fact that early catheter removal following laparoscopic radical prostatectomy is feasible [24-26]. However, as no standard timing for catheter removal has been defined, we chose to maintain it for a total of 2 to 3 weeks after the procedure. Moreover, we do not perform retrograde cystography to assess the integrity of the anastomosis before catheter removal, as this approach has been proved safe in men who underwent radical prostatectomy, and their catheter was removed on the $4^{\text {th }}$ to $10^{\text {th }}$ postoperative day [24].

In this study, urinary continence at 3 months following surgery was $92.85 \%$ (only 2 patients were incontinent). However, none of the men complained of urinary leakage at 6- and 12-month follow-up visits. Moreover, none of the patients developed urethral stricture. It is worth mentioning that bladder neck preservation was performed in all cases as described previously [27]. This could have improved the early continence rate and reduced the number of urethral strictures.

\section{Conclusions}

We are encouraged by our initial results of a running suture single knot technique for vesicourethral anastomosis, which we believe allows for safe, feasible and efficient re-establishment of the continuity of the lower urinary tract during laparoscopic radical prostatectomy. We will continue to evaluate this method further on a larger group of patients, as well as to compare it with other established techniques.

\section{References}

1. Boyle P, Ferlay J. Cancer incidence and mortality in Europe, 2004. Ann Oncol 2005; 16: 481-8.

2. Parkin DM, Ferlay J, Curado MP, et al. Fifty years of cancer incidence: CI5 I-IX. Int J Cancer 2010; 127: 2918-27.

3. Arnold M, Karim-Kos HE, Coebergh JW, et al. Recent trends in incidence of five common cancers in 26 European countries since 1988: analysis of the European Cancer Registry database. Eur J Cancer 2013; pii: S0959-8049(13)00842-3.

4. Atkins D, Best D, Briss PA, et al.; GRADE Working Group.Grading quality of evidence and strength of recommendations. BMJ 2004; 328: 1490.

5. Guyatt GH, Oxman AD, Vist GE, et al.; GRADE Working Group. GRADE: an emerging consensus on rating quality of evidence and strength of recommendations. BMJ 2008; 336: 924-6.

6. Potosky AL, Legler J, Albertsen PC, et al. Health outcomes after prostatectomy or radiotherapy for prostate cancer: results from the prostate cancer outcomes study. I Natl Cancer Inst 2000; 92: 1582-92.

7. Stanford JL, Feng Z, Hamilton AS, et al. Urinary and sexual function after radical prostatectomy for clinically localized prostate cancer: the prostate cancer outcomes study. JAMA 2000; 283: 354-60.

8. Shichiri Y, Kanno T, Oida T, Kanamaru H. Facilitating the technique of laparoscopic running urethrovesical anastomosis using Lapra-ty absorbable suture clips. Int J Urol 2006; 13: 192-4.

9. Van Velthoven RF, Ahlering TE, Peltier A, et al. Technique for laparoscopic running urethrovesical anastomosis: the single knot method. Urology 2003; 61: 699-702.

10. Rozet F, Fournier G, Cathelineau X, et al. Vesico-urethral anastomosis during total laparoscopic prostatectomy. Ann Urol (Paris) 2006; 40: 50-6.

11. Katz R, Nadu A, Olsson LE, et al. A simplified 5-step model for training laparoscopic urethrovesical anastomosis. J Urol 2003; 169: 2041-4.

12. Menon M, Tewari A, Peabody JO, et al. Vattikuti Institute prostatectomy, a technique of robotic radical prostatectomy for management of localized carcinoma of the prostate: Experience of over 1100 cases. Urol Clin North Am 2004; 31: 701-17.

13. Szydelko T, Tuchendler T, Litarski A, et al. Laparoscopic Anderson-Hynes procedure as a treatment of ureteropelvic junction obstruction caused by fibroepithelial polyp. Videosurgery Miniinv 2013; 8: 361-3. 
14. Golab A, Slojewski M, Sikorski A. Simplified laparoscopic technique for the treatment of long distal ureteral stenosis. Videosurgery Miniinv 2013; 8: 346-51.

15. Stránský P, Eret V, Ürge T, et al. Laparoscopic adrenalectomy for metachronous ipsilateral metastasis following nephrectomy for renal cell carcinoma. Videosurgery Miniinv 2013; 8: 221-5.

16. Stojewski M, Chłosta P, Myślak M, et al. Single-session laparoscopic cystectomy and nephroureterectomy. Videosurgery Miniinv 2013; 8: 158-61.

17. Breyer BN, McAninch JW. Management of recalcitrant bladder neck contracture after radical prostatectomy for prostate cancer. J Urol 2011; 185: 390-1.

18. Hakimi AA, Blitstein J, Feder M, et al. Direct comparison of surgical and functional outcomes of robotic-assisted versus pure laparoscopic radical prostatectomy: single-surgeon experience. Urology 2009; 73: 119-23.

19. Hora M, Stránský P, Klečka J, et al. Managing urine leakage following laparoscopic radical prostatectomy with active suction of the prevesical space. Videosurgery Miniinv 2013; 8: 49-54.

20. Ouzaid I, Xylinas E, Ploussard G, et al. Anastomotic stricture after minimally invasive radical prostatectomy: what should be expected from the van velthoven single-knot running suture? J Endourol 2012; 26: 1020-5.

21. Gallo L, Perdonà S, Autorino R, et al. Vesicourethral anastomosis during radical retropubic prostatectomy: does the number of sutures matter? Urology 2007; 69: 547-51.

22. Branco AW, Kondo W, de Camargo AH, et al. Laparoscopic running urethrovesical anastomosis with posterior fixation. Urology 2007; 70: 799-802.

23. Zarrelli G, Mastroprimiano G, Giovannone R, et al. Knotless "three-U-stitches" technique for urethrovesical anastomosis during laparoscopic radical prostatectomy. Int J Urol 2013; 20: 441-4.

24. Dalton DP, Schaeffer AJ, Garnett JE, Grayhack JT. Radiographic assessment of the vesicourethral anastomosis directing early decatheterization following nerve-sparing radical retropubic prostatectomy. J Urol 1989; 141: 79-81.

25. Hakimi AA, Faleck DM, Sobey S, et al. Assessment of complication and functional outcome reporting in the minimally invasive prostatectomy literature from 2006 to the present. JU Int 2012; 109: 26-30.

26. James P, Glackin A, Doherty A. Safe removal of the urethral catheter 2 days following laparoscopic radical prostatectomy. ISRN Oncol 2012; 2012: 912642.

27. Chłosta PL, Drewa T, Jaskulski J, et al. Bladder neck preservation during classic laparoscopic radical prostatectomy - point of technique and preliminary results. Videosurgery Miniinv 2012; 7: 89-95.

Received: 24.10 .2013 , accepted: 2.12 .2013 